\title{
Haemonchus resistente à lactona macrocíclica em caprinos naturalmente parasitados
}

\author{
Macrocyclic lactone-resistant strains of Haemonchus in naturally infected goats
}

\author{
Mary Jane Tweedie de Mattos $^{1}$ Carlos Marcos Barcellos de Oliveira ${ }^{2}$ \\ Aline Silva Gouvea ${ }^{3}$ Cíntia Bisogno Andrade ${ }^{3}$
}

\section{RESUMO}

\begin{abstract}
O ivermectin, antiparasitário amplamente utilizado em caprinos jovens, foi avaliado sobre nematódeos gastrintestinais, em todas as fases parasitárias. Doze caprinos jovens, naturalmente parasitados foram utilizados no experimento, sendo um grupo de seis animais medicado com ivermectin, na dose de $200 \mu \mathrm{g} / \mathrm{kg}$ v.o. e o outro grupo utilizado como controle. Para a avaliação, utilizou-se o teste de redução na contagem de ovos (FECR), redução de larvas infectantes $e$ carga parasitária. Amostras fecais de caprinos foram coletadas no dia da medicação (dia zero), aos sete e catorze dias. No décimo quarto dia pós-medicação, todos os caprinos foram sacrificados, para a coleta de helmintos e cálculo da carga parasitária total. A redução do número de ovos (FECR) e a eficácia sobre adultos foi de 42,10\% e 32,62 \%, respectivamente.O gênero Haemonchus representou $100 \%$ da população do grupo medicado e $99,58 \%$ do grupo controle. Estes resultados indicam que os caprinos já estavam parasitados por Haemonchus resistente ao ivermectin.
\end{abstract}

Palavras-chave: ivermectin, caprinos, resistência.

\section{ABSTRACT}

Ivermectin, an antiparasitic drug that is widely used in young goats, was avalied as to its effect on gastrointestinal nematodes, at all parasitic stages. Twelve naturally infected young goats were studied: six of them received $200 \mu \mathrm{g} / \mathrm{kg}$ of ivermectin orally, while the other six was used as controls. The faecal egg count reduction (FECR) test, the larval culture and the worm burden was estimated. Faecal samples was collected from the goats on the day of medication (day zero), at seven and at fourteen days. All the goats were killed fourteen days after treatment; helminths were collected and the total parasite load was estimated. FECR and the efficiency of the drug on adult nematodes was $42.10 \%$ and $32.62 \%$, respectively. The genus
Haemonchus represented $100 \%$ of the population in the treated group and $99.58 \%$ of the control group. These results show that the goats had already been infected by ivermectin-resistant Haemonchus strains.

Key words: ivermectin, goats, resistance.

\section{INTRODUÇÃO}

Os caprinos representam uma fonte de proteína de origem animal, tornando a caprinocultura uma atividade de relevante importância socioeconômica, tanto no Brasil como no mundo (VIEIRA, 1999). Entretanto, a atividade é limitada, pelo desenvolvimento das parasitoses gastrintestinais, principalmente ocasionadas por Haemonchus. As verminoses que são controladas basicamente pela utilização de anti-helmínticos foram afetadas seriamente pelo aumento no desenvolvimento da resistência dos helmintos a essas drogas. Os primeiros relatos se referiam à resistência dos helmintos frente à aplicação dos benzimidazóis e levamisoles, e com o descobrimento em 1981, de um grupo químico de antihelmíntico distinto, as avermectinas, surgiu uma alternativa de tratamento (GOPAL et al.1999), que têm sido considerado até hoje, como um principio ativo potente para o controle das parasitoses de animais domésticos. Entretanto, a resistência ao ivermectin têm sido registrada em caprinos parasitados por Ostertagia

\footnotetext{
${ }^{1}$ Médico Veterinário, Mestre. Professor Adjunto, Departamento de Patologia Clinica Veterinária. Faculdade de Veterinária, Universidade Federal do Rio Grande do Sul (UFRGS), Av. Bento Gonçalves, 9090, 91540-000, Porto Alegre, RS. E-mail: mary.gomes@ufrgs.br. Autor para correspondência.

${ }_{2}^{2}$ Médico Veterinário, Doutor, Professor Titular, Departamento de Patologia Clinica Veterinária, Faculdade de Veterinária, UFRGS.

${ }^{3}$ Acadêmico da. Faculdade de Veterinária, UFRGS.
} 
circumcincta na Checoslováquia (VARADY et al., 1993), na Nova Zelândia (POMROY et al., 1992), na África (GATONGI et al., 2003) e no Reino Unido (JACKSON et al., 1992). Relatos de resistência em Haemonchus contortus à aplicação do ivermectin são descritos na Austrália (LE JAMBRE, 1993), Estados Unidos da América (TERRIL et al. 2001) e no Brasil ( MATTOS et al. 1997).

No Estado do Rio Grande do Sul, a caprinocultura é caracterizada por pequenas propriedades, cujas famílias utilizam esta atividade como meio de sobrevivência, havendo um envolvimento de todos os integrantes no manejo dos animais. Pesquisas realizadas neste Estado evidenciaram que os helmintos mais prevalentes são Haemonchus e Trichostrongylus (CARDOSO \& OLIVEIRA, 1993) e Haemonchus e Ostertagia (MATTOS \& BASTOS, 2000). Para o controle das parasitoses dos animais jovens, os criadores utilizam a lactona macrocíclica, denominada ivermectin. Pesquisas realizadas anteriormente em caprís evidenciaram que a eficácia do ivermectin frente às infecções por nematódeos gastrintestinais pode variar de acordo com fatores como época do ano e manejo dos caprinos. Assim sendo, o presente experimento teve como objetivo avaliar com maior segurança a eficácia deste princípio ativo sobre ovos, larvas e adultos de helmintos, em animais naturalmente parasitados .

\section{MATERIAL E MÉTODOS}

Os caprinos foram selecionados a partir de informações fornecidas pelos proprietários, de que os mesmos não ganhavam peso e que embora fossem medicados com antiparasitários periodicamente, alguns animais morriam. Os animais utilizados neste experimento eram provenientes de 2 propriedades rurais da Grande Porto Alegre, e não haviam recebido qualquer medicação anti-helmíntica há pelo menos 30 dias antes do experimento.Todos os animais selecionados foram removidos para a cabanha da Faculdade de Veterinária/UFRGS, em Porto Alegre, própria para esta espécie animal. Inicialmente permaneceram em adaptação alimentar por 15 dias, sendo que, nos primeiros três dias só receberam forragem de feno, duas vezes ao dia. Após este período receberam além de forragem de feno, duas vezes ao dia, um concentrado não medicamentoso uma vez ao dia e água à vontade. As baias eram de piso ripado e elevado do chão e higienizadas diariamente. No dia da chegada na cabanha, foram pesados e identificados com brinco numerado. Amostras fecais individuais foram coletadas diretamente do reto, identificadas e mantidas em refrigeração até o processamento, para a contagem de ovos e cultura de larvas para futura formação dos lotes. Os animais foram separados através de sorteio utilizando como critério o número de ovos e procedência, de modo que o opg médio fosse semelhante nos dois grupos. Cada grupo tinha representantes das duas procedências na mesma proporção. No dia da medicação, os caprinos foram novamente pesados para cálculo do volume de antihelmíntico a ser administrado. O experimento foi realizado com 12 caprinos naturalmente parasitados por nematódeos gastrintestinais, sem raça definida, com 4-5 meses de idade, machos e com peso médio de $11,36 \mathrm{~kg}$. Estes animais foram divididos em 2 grupos com seis animais: o primeiro, recebeu 200 $\mu \mathrm{g} / \mathrm{kg}$ de ivermectin, via oral e o segundo considerado como controle, recebeu o mesmo volume de água (VERCRUYSSE et al., 2001). Amostras fecais de todos os caprinos foram coletadas no dia da medicação (dia zero), aos sete e aos catorze dias posteriores. Estas foram processadas para a contagem de ovos e identificação de larvas infectantes, respectivamente, através dos Métodos de GORDON \& WHITLOCK (1939) e ROBERTS \& O'SULLIVAN (1950), no Laboratório de Helmintologia da Faculdade de Veterinária/ UFRGS. No décimo quinto dia, todos os caprinos após serem submetidos a um jejum sólido por 12 horas foram sacrificados, para a coleta de helmintos gastrintestinais, segundo a metodologia de descrita por UENO \& GONÇALVES (1998). Para efeito da contagem de helmintos foram consideradas, amostra de $10 \%$ do abomaso e do intestino delgado e 100 $\%$ do conteúdo do intestino grosso.

Para calcular a eficácia do ivermectin em relação à redução do número de ovos por grama de fezes (opg), foi utilizada a fórmula abaixo (COLES \& ROUSCH, 1992):

A eficácia do ivermectin sobre a população de helmintos presentes nos dois grupos foi avaliada através da fórmula descrita por: UENO \& GONÇALVES (1998):

Os resultados foram avaliados através da análise da variância. Foram calculados os resíduos da análise da variância com o software SAS, e com esses resíduos foram calculados os coeficientes de correlação parcial utilizando o software SPSS (MONTGOMERY, 1997). 


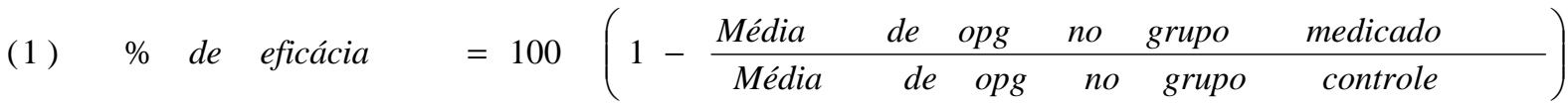

$$
E=\frac{n^{\mathrm{o}} \text { médio de hel } \min \text { tos no grupo controle }-n^{\mathrm{o}} \text { médio de hel mintos do medicado } \times 100}{n^{\mathrm{o}} \text { médio de hel } \min \text { tos no grupo controle }}
$$

\section{RESULTADOS}

A redução no opg no grupo medicado foi de $42,10 \%$ entre o dia zero e catorze dia pós tratamento, passando de 3583 para 3050 ovos de Trichostrongyloidea (Tabela 1). No grupo controle, aumentou de 3100 para 5267 ovos, no mesmo período (Tabela 1). A identificação genérica das larvas infectantes no grupo medicado acusou a presença de Haemonchus com percentuais de 95\%, $89 \%$ e $93 \%$ e Ostertagia com os percentuais de $5 \%, 11 \%$ e $7 \%$, nos dias zero, sete e catorze, respectivamente. Em relação ao grupo controle, no dia zero, foram observadas larvas infectantes de Haemonchus (95\%) e Ostertagia (5\%). Nos dias sete e catorze, foram identificadas larvas infectantes de Haemonchus e Ostertagia com os mesmos percentuais de $97 \%$ e $3 \%$ respectivamente.

O gênero Haemonchus representou $100 \%$ e $99,58 \%$ da população, nos grupos medicados e controle, respectivamente (Tabela 2). Não foram encontrados adultos do gênero Ostertagia no grupo medicado. A eficácia sobre as formas adultas de Haemonchus foi de 32,62 \%. Não foram encontrados helmintos no intestino delgado e grosso. A Tabela 2 mostra que o número de fêmeas nos grupos medicado e controle representou 52,20 $\%$ e 58,47 \% da população de Haemonchus, respectivamente. Houve uma associação positiva direta entre a carga parasitária e opg $(\mathrm{r}=+0,487$, $\mathrm{p}<0,016)$.

Tabela 1 - Número de ovos de Trichostrongyloidea por grama de fezes, em caprinos nos grupos medicado com ivermectin e controle (média e amplitude).

\begin{tabular}{lccc}
\hline Grupo & Dias 0 & Pós - medicação 7 & 14 \\
\hline Medicado & 3583 & 1133 & 3050 \\
& $(300-8200)$ & $(100-2400)$ & $(100-10200)$ \\
Controle & 3100 & 2850 & 5267 \\
& $(700-7200)$ & $(1800-5700)$ & $(500-13300)$ \\
\hline
\end{tabular}

Legenda:(entre parênteses= número mínimo e máximo de ovos encontrados por animal)

\section{DISCUSSÃO}

A redução de $32 \%$ sobre o número total de helmintos e de $42 \%$ sobre o número de ovos por grama de fezes indicam a presença de estirpes de Haemonchus resistentes a uma aplicação oral de ivermectin, na dose de $200 \mu \mathrm{g} / \mathrm{kg}$, em caprinos naturalmente parasitados considerando que estes índices são bem inferiores aos índices de 90-95\%, propostos por COLES \& ROUSCH (1992), VERCRUYSSE et al. (2001), TAYLOR et al. (2002), para que um anti-helmíntico seja aceito como eficaz.

No presente experimento, não foram observados adultos de Ostertagia no grupo medicado embora na última cultura de larvas tenha sido detectado larvas deste gênero. Isto provavelmente ocorreu pela presença de ovos que ficaram mais tempo no trato gastrintestinal.

$\mathrm{Na}$ África, GATONGI et al. (2003), ao comparar dois grupos de caprinos experimentalmente infectados (medicado e controle), verificou que a eficácia do ivermectin foi de $69,1 \%$ sobre a redução de ovos e $73,6 \%$ sobre o número de helmintos encontrado no abomaso, índices superiores observados no presente estudo, mas ainda abaixo dos valores aceitáveis para que o princípio ativo seja considerado como eficaz. Pesquisas realizadas por MESQUITA \& HEES (1992), no Rio de Janeiro, evidenciaram uma eficácia do ivermectin de $100 \%$, em caprinos naturalmente parasitados por Haemonchus e Cooperia através da redução de opg, o que diverge deste experimento. No Rio Grande do Sul, MATTOS et al. (1997) realizaram um teste de eficácia do ivermectin em caprinos e verificaram que a redução do número de ovos de Ostertagia foi de $47,61 \%$, resultados estes que se assemelham aos da presente pesquisa, porém, neste último experimento, os animais estavam parasitados por Haemonchus (95\%) e Ostertagia (5\%). BORGSTEEDE et al. (1996) verificaram que em caprinos parasitados por Ostertagia, na África do Sul, a eficácia do ivermectin foi de $100 \%$. TERRIL et al. (2001) nos USA relataram resistência de 
Tabela 2- Número total e médio de helmintos identificados no abomaso de caprinos, no grupo medicado com ivermectin e no grupo controle.

\begin{tabular}{|c|c|c|c|c|c|c|}
\hline \multirow{2}{*}{ Grupo } & \multicolumn{3}{|c|}{ Haemonchus } & \multicolumn{3}{|c|}{ Osterlagia } \\
\hline & Machos & Fêmeas & Total & Machos & Fêmeas & Total \\
\hline \multicolumn{7}{|c|}{ Medicado } \\
\hline Total & 760 & 830 & 1590 & 0 & 0 & 0 \\
\hline \multirow[t]{2}{*}{ Média } & 126,66 & 138,33 & & 0 & 0 & 0 \\
\hline & $(0-280)$ & $(0-410)$ & & & & \\
\hline \multicolumn{7}{|c|}{ Controle } \\
\hline Total & 980 & 1380 & 2360 & 0 & 10 & 10 \\
\hline \multirow[t]{2}{*}{ Média } & 163,33 & 230 & & 0 & 1,66 & \\
\hline & $(10-700)$ & $(20-960)$ & & & & \\
\hline
\end{tabular}

helmintos frente à aplicação de ivermectin em caprinos, com uma redução média no número de ovos de Haemonchus de 78\%.

As diferenças constatadas pelos autores, nos percentuais de eficácia, provavelmente sejam decorrentes das diferentes pressões de uso deste princípio ativo em cada região estudada. Pesquisas realizadas por GILL et al. (1998), PAIEMENT (1999) e SANGSTER \& GILL (1999) indicaram que, in vivo, a resistência a endectocidas se deve a uma redução na sensibilidade dos efeitos das avermectinas sobre o desenvolvimento e motilidade larvária, o que implica a inibição da atividade da bomba faringeana e da musculatura somática. A resistência do $\boldsymbol{H}$. contortus ao ivermectin foi associada a modificações das subunidades do receptor $\mathrm{GluCl}$ e/ou a expressão aumentada de uma glicoproteina de membranaGlicoproteina $\mathrm{P}(\mathrm{GpP})$ que possivelmente impeçam que o princípio ativo atinja as concentrações ativas da molécula antiparasitária no receptor de glutamato do parasito resistente (MOTTIER \& LANUSSE, 2001).

No presente experimento, no grupo controle, o número médio de adultos de Haemonchus $(393,33)$ foi menor do que o encontrado (365) por CHARLES (1989) no município de Petrolina e, menor do que o relatado $(893,09)$ por CARDOSO \& OLIVEIRA (1993), na Grande Porto Alegre-RS. Estes valores provavelmente são diferentes em função da época do ano e da faixa etária dos animais.

\section{CONCLUSÃO}

O ivermectin não foi eficaz sobre ovos e adultos de Haemonchus, caracterizando um problema de resistência nos animais oriundos de duas propriedades. No Estado do Rio Grande do Sul, a sua utilização só poderá ser justificada em rebanhos que possuam monitoramento laboratorial.

\section{REFERÊNCIAS BIBLIOGRÁFICAS}

BORGSTEEDE, F.H.M.; PEKELDER, J.J.; DERCKSEN, D.P. Anthelmintic resistant nematodes in goats in the Netherlands. Veterinary Parasitology, v.5, p.83-87. 1996.

CARDOSO, J.L.S.; OLIVEIRA, C.M.B. de. Fauna parasitária de caprinos da grande Porto Alegre. Revista Brasileira de Parasitologia Veterinária, v.2, p.57-60, 1993.

CHARLES, T.P. Seasonal prevalence of gastrointestinal nematodes of goats in Pernambuco State, Brazil. Veterinary Parasitology, v.30, p.335-343, 1989.

COLES, G.C.; ROUSCH, R.T. Slowing the spread of anthelmintic resistant nematodes of sheep and goats in the United Kingdom. Veterinary Record, v.130, p.505-510, 1992.

GATONGI, P.M. et al. Susceptibility to IVM in a field strain of Haemonchus contortus subjected to four treatments in a closed sheep-goat flock in kenya. Veterinary Parasitology, v.110, n.34, p.235-240, 2003.

GILL, J. et al. Evidence of multiple mechanisms of avermectin resistance in Haemonchus contortus comparison of selection protocols. International Journal for Parasitology, v.28, p.783789, 1998.

GOPAL, R.M.; POMROY,W.E.; WEST, D.M. Resistance of field isolates of Trichostrongylus colubriformis and Ostertagia circumcincta to ivermectin. International Journal for Parasitology, v.29, p.781-786, 1999.

GORDON, H.M.; WHITLOCK, H.V. A new technique for counting nematode eggs in sheep faeces. Journal of the Council for Scientific and Industrial Research, v.12, p.50-52, 1939.

JACKSON, F.; JACKSON, E.; COOP, R.L. Evidence of multiple anthelmintic resitance in a strain of Teladorsagia circumcincta (Ostertagia circumcincta) isolated from goats in Scotland. Research Veterinary Science, v.55, p.371-374, 1992. 
LE JAMBRE, L.F. Ivermectin-resistant Haemonchus contortus in Australia. Australian Veterinary Journal, v.70, p.357, 1993.

MATTOS, M.J.T. de; GERMER, M.; CASTRO, E.S. Eficácia do ivermectin sobre endoparasitos de caprinos, no RS. In: CONGRESSO ESTADUAL DE MEDICINA VETERINARIA, 13., 1997, Gramado, RS. Anais... Gramado : Sociedade de Veterinária do Rio Grande do Sul, 1997. p.198.

MATTOS, M.J.T. de.; BASTOS, C.D. Parasitoses de caprinos no município de Viamão. Brazilian Journal of Veterinary Science,v.7, n.1, p.217, 2000.

MESQUITA, M.; HEES, S.J. Teste comparativo da eficácia de ivermectina oral em caprinos perante um outro anti-helmintico de uso rotineiro. A Hora Veterinária, v.66, p.23-26, 1992.

MONTGOMERY, D.C. Design and analysis of experiments. New York : John Wiley \& Sons, 1997. 704p.

MOTTIER, L.; LANUSSE, C. Bases moleculares de la resistencia a fármacos. Revista de Medicina Veterinaria, v.82, n.2, p.74$85,2001$.

PAIEMENT, J.; PRICHARD, R.K.; RIBEIRO, P. Haemonchus contortus: characterization of a glutamate binding site in unselected and ivermectin selected larvae and adults. Experimental Parasitology, v.92, n.1, p.32-39, 1999.

POMROY, W.E.; WHELAN, N.; ALEXANDER, A.M. Multiple resistance in goat-derived Ostertagia and efficacy of moxidectin and combinations of other anthelmintics. New Zealand Veterinary Journal, v.40, p.76-78, 1992.
ROBERTS, F.H.S.; O'SULLIVAN, J.P. Methods for egg counts and larval cultures for strongyles infesting the gastrointestinal tract of cattle. Australian Journal of Agricultural Research,v.1, p.99, 1950.

SANGSTER, N.C.; GILL, J. Pharmacology of anthelmintic resistance. Parasitology Today, v.15, p.141-146, 1999.

TAYLOR, M.A; HUNT, K.R.; GOODYEAR, K.L. Anthelmintic resistance detection methods. Veterinary Parasitology, v.103, p.183-194, 2002.

TERRIL, T.H., et al. Anthelmintic resistance on goat farms in Georgia: efficacy of anthelmintics agains gastrointestinal nematodes in two selected goat herds. Veterinary Parasitology, v.97, n.4, p.261-268, 2001.

UENO, H.; GONÇALVES, P.C. Manual para diagnóstico das helmintoses de Ruminantes. 4.ed. Japão : JICA, 1998. 166p.

VARADY, M. et al. Multiple anthelmintic resistance of nematodos in imported gotas. Veterinary Record, v.132, p.387$388,1993$.

VERCRUYSSE, J. et al. International harmonisation of anthelmintic efficacy guidelines. Veterinary Parasitology, v.96, n.3, p.171-193, 2001.

VIEIRA, L.S. Epidemiologia e controle da nematodeose gastrintestinal dos caprinos. In: CONGRESSO PERNAMBUCANO DE MEDICINA VETERINÁRIA, 4., 1999, Recife. Anais... Recife : Sociedade Pernambucana de Medicina Veterinária, 1999. p.123-128. 